\title{
Economic policy and market imperfections in an unstable economic and financial environment in Europe and the Middle East
}

\author{
Christian Richter $^{1} \cdot$ Sandar Win ${ }^{2}$
}

Published online: 10 September 2018

(C) Springer-Verlag GmbH Germany, part of Springer Nature 2018

The financial crisis of 2007 highlighted the challenges, which economic policy is facing: Monetary policy has to deal with unstable and unsustainable financial markets where economic policy failed to set a sustainable framework of regulations.

Of course, the financial crisis is only the most prominent crisis and only serves as an example. The economic cost of the financial crisis have not yet been digested when new political events such as the BREXIT and calls for protectionism cause further - not only economic - uncertainty. As political events cause uncertainty, market imperfections cause uncertainty as well. In other words, (economic) policy makers have to increasingly operate under imperfect knowledge and uncertainty than let's say before the financial crisis. We focus in this Special Issue on two completely contrary economic situations: Europe and the Middle East. It is needless to say that both regions politically as well as economically connected with each other as recent events have shown. Yet, the economic challenges, both are facing could not be more different.

The Arab spring raised hopes of a new beginning in this region politically as well as economically. As it turned out, economically the situation in the MENA region is today more severe than before. Moreover, the events of the Arab Spring have long spilled over into Europe and other neighbouring areas emphasising the interconnectivities of today's world.

On the other hand, the Eurozone is still busy to deal with the fallouts of the financial crisis and its own economic and political problems in particular. Economically, the

Christian Richter

christian.richter@guc.edu.eg

Sandar Win

sandar.win@beds.ac.uk

1 Department of Economics, Faculty of Management Technology, German University in Cairo, New Cairo City, Egypt

2 Department of Finance, University of Bedfordshire Business School, University of Bedfordshire, Luton, UK 
Eurozone is still digesting the financial crisis and the Eurozone crisis, whilst politically the Eurozone has to deal with the BREXIT. These counter-poles of problems offer interesting insights on the spectrum that economic policy is facing nowadays.

Having said that, the aim of this special issue is not necessarily to find solutions to these problems, but first of all to highlight them. It is in many cases not quite clear how economic policy may deal with all these challenges at this point and further research is required.

However, we do offer hints on how problems could be overcome, for example by looking into history. Some problems have occurred in the past and it is worthwhile to investigate what the consequences were then or how they were overcome, for example with respect to a non-optimal currency are.

John Ryan and John Loughlin take an historical perspective to study the Latin Monetary Union (LMU), Scandinavian Monetary Union (SMU), and the AustroHungarian Monetary Union (AHMU) with the aim of deriving lessons for European Monetary Union (EMU). After examining each of the historical monetary unions from this perspective, the article concludes that none of them ever truly conformed to Mundell's concept, nor does the EMU. Nevertheless, the article argues that some lessons may be learned from these historical experiences. First, it is necessary that there exist robust institutions such as a common central bank and a unified fiscal policy in order to withstand external shocks. The three early unions could not withstand the shock of WWI. Another important lesson is that continuing national rivalries can undermine any monetary union.

The following paper by Dina Yousry and Christian Richter focusses on Egypt. It examines the extent to which women's education, fertility rate, corruption and urbanization affects long-term economic growth in Egypt. They also analyse the impact of female education and fertility rate on economic growth, and examine the relationship between economic growth and corruption. The results suggest that investments in female education can reduce the fertility rate. As the fertility rate increases real GDP growth decreases with a lag of 2 years. The immediate effect of higher female education on real GDP is negative but overall it has a positive impact when lags are taken into account. Interestingly, the immediate effect of urbanization on real GDP growth was negative and turned to be positive in the long run. Finally, corruption was found to have a negative impact on GDP growth in Egypt over their studied time period.

After the sociological impacts on GDP we focus on banks' risk management Studies, written by Sandar Win. Win uses the Renn and Swaton's framework of perspectives in risk management studies to analyse the literature. Win finds that prior studies on banks' risk management have extensively focused on market-based judgements of financial risks and the ex-post calibration of different factors and bank lending. By identifying the significance of the relationships between factors, she finds that they neither provide information about how these factors influence each other, nor theoretical links through which these factors interact. This paper makes a significant contribution to banking studies as the 2008 financial crisis proved that interactions between financial regulators and the banks cannot be understood with simplified models because they are much more complex and banks' compliance and non-compliance to regulations depend on their intrinsic motivations. Optimisation tends to oversimplify the costs and benefits of financial liberalisation and focuses on 
the outcome through analysing aggregate changes such as changes in total credit volume by macro level economic policies. Hence, there is a significant gap in analysing micro level implementation of macro level policies. It would be interesting to study banks' risk management in the light of sociological perspective to understand the degree of controls that regulators have on banks and the institutional limitations that they encounter in regulatory enforcements.

The following paper by Belke and Wiedmann looks at the Dissecting Long-run and Short-run Causalities between Monetary Policy and Stock Prices. Using a Cointegrated Vector-Autoregressive (CVAR) model to analyze the long-run behavior and short-run dynamics of stock markets across five developed and three emerging economies, they check whether liquidity conditions play an important role for stock market developments. As an innovation, liquidity conditions enter the analysis from three angles: in the form of a broad monetary aggregate, the interbank overnight rate and net capital flows which represent the share of global liquidity that arrives in the respective country. A second objective is to understand whether central banks are able to influence the stock market.

The last paper by Thede in this special issue is slightly different from the other ones. The author does not necessarily assume imperfect markets. What makes this paper interesting is that social insurance does not necessarily lead to low-skill unemployment in economies specialized in skill-intensive production. It is commonly argued that social insurance by increasing cost lead to an offshoring of low skill workers. Thede argues that social insurance improves productivity - even in case of low skill workers which in turn may counteracts adverse pressures of offshoring and/or trade in the low-skill labor market. This implies that social insurance can be sustained under globalization pressure, which stands in stark contrast to the view that it necessarily triggers a cost effect leading to a 'race to the bottom' between Western countries downsizing their welfare systems. As a result, social insurance does not actually introduce a market distortion into the labour market. On the contrary, it can be seen as a remedy to an imperfect labour market. Therefore, instead of dismantling the social insurance system in a way to ever more liberalise labour markets, the social insurance system should be maintained and improved. As such the social insurance is part of the solution and not the problem.

All papers were presented at the Annual Conference of the International Network for Economic Research in Luton in 2015. The editors wish to thank the researchers and referees who have evaluated the papers for their valuable contributions. 